\title{
Frequent genetic alterations and reduced expression of the Axin1 gene in oral squamous cell carcinoma: Involvement in tumor progression and metastasis
}

\author{
CHUAN-XIANG ZHOU and YAN GAO \\ Department of Oral Pathology, Peking University School and Hospital of Stomatology, \\ 22 South Avenue, Zhong-Guancun, Hai-Dian District, Beijing, P.R. China
}

Received September 4, 2006; Accepted October 5, 2006

\begin{abstract}
The aims of this study were to analyze the genetic alterations and expression levels of the Axin1 gene in oral squamous cell carcinoma (OSCC), to evaluate its clinical importance and to clarify whether the Axin1 gene is involved in the pathogenesis of OSCC. Mutation analysis of the Axin1 gene was performed by denaturing high performance liquid chromatography (DHPLC) and DNA sequencing in 44 OSCC samples. Meanwhile, Axin1 protein expression was investigated by immunohistochemistry in these samples. Aberrant profiles were detected by DHPLC screening in 26 different OSCC cases. After sequencing analysis, four mutations and five polymorphisms were identified. One case of poorly differentiated OSCC with metastasis contained two mutations: one revealed a $\mathrm{T}>\mathrm{G}$ substitution at nucleotide 324 in exon 1 , resulting in a glycine to stop codon substitution at amino acid residue 108; the other revealed an $A>G$ heterozygous mutation in intron 7 , located very near to exon 8 . In another two patients with moderately differentiated OSCC and metastasis, a $\mathrm{G}>\mathrm{T}$ heterozygous mutation at codon 488 in exon 5 and a $\mathrm{C}>\mathrm{G}$ substitution at the intron $5+26$ position was detected, respectively. Five polymorphisms were all frequent and localized at positions of codon $254(\mathrm{GAT} \rightarrow \mathrm{GAC})$, codon 429 (GTC $\rightarrow$ ATC), codon $525($ GAC $\rightarrow$ GAT), codon $609(\mathrm{GCT} \rightarrow \mathrm{GCC})$, and intron $4+17(\mathrm{G}>\mathrm{A})$, with a frequency of $39 \%, 8 \%, 6 \%, 13 \%$ and $9 \%$, respectively. Immunoreactivity for Axin1 was strongly positive in normal stratified squamous epithelium but significantly reduced expression of Axin 1 was shown in most of the 44 tumor specimens (35/44), especially in poorly differentiated tumors with metastasis. These results suggest that mutational inactivation and reduced expression
\end{abstract}

Correspondence to: Dr Yan Gao, Department of Oral Pathology, Peking University School and Hospital of Stomatology, 22 South Ave., Zhong-Guancun, Hai-Dian District, Beijing, P.R. China E-mail: gaoyan0988@263.net

Key words: Axin1, mutation, polymorphism, denaturing high performance liquid chromatography, immunohistochemistry, differentiation, metastasis, oral squamous cell carcinoma of the Axin1 gene may play a pivotal role in OSCC carcinogenesis and metastasis.

\section{Introduction}

Axin1 was originally identified as the product of the mouse fused locus, and has been shown to play a pivotal role in controlling embryonic axis formation (1). To date, Axin1 has been suggested in at least three different signaling pathways: the stress activated protein kinase (SAPK), TGF- $\beta$ and Wnt signaling pathway, which can help mediate cell survival or apoptosis and subsequently be involved in carcinogenesis. The Wnt signaling pathway is not only crucial to embryonic development but also critical in tumorigenesis $(2,3)$. The central player is $B$-catenin, which is a transcription cofactor with $\mathrm{T}$ cell factor/lymphoid enhancer factor (TCF/ LEF) in the Wnt pathway and can subsequently regulate the target gene expression. Axin1 has been shown to interact with $B$-catenin and promote its phosphorylation that is required for the ubiquitination and the subsequent degradation of $\beta$ catenin. The effect of Axin 1 on $\beta$-catenin concentration indicates that Axin1 can negatively regulate the Wnt signaling pathway and may be a tumor suppressor gene $(4,5)$. The TGF- $\beta$ signaling pathway also plays an important role in carcinogenesis. Smads are key effector proteins in the TGF- $\beta$ signaling pathway in that phosphorylated Smads can translocate into the nucleus and regulate the transcription of the target genes (6). Axin1 has been shown to interact with Smad3 and Smad7, two of the TGF- $\beta$ effectors, and positively regulate the TGF- $\beta$ signaling pathway, subsequently reducing proliferation and inducing differentiation $(7,8)$. In addition, overexpression of Axin1 in tumor cells promotes the SAPK/JNK pathway and can induce apoptosis through the activation of MEKK (mitogen activated protein/extracellular regulated kinase kinase) (9).

Squamous cell carcinoma is one of the most common malignancies of the head and neck and has a poor prognosis in spite of recent advances in radiotherapy and chemotherapy (10). Although Axin1 gene mutation or reduced expression has been reported in some kinds of tumors, such as hepatocellular carcinoma, colon carcinoma, and ovarian endometrioid adenocarcinoma, to our knowledge, whether Axin 1 is also involved in the pathogenesis of OSCC remains uncertain (11-14). Yeh et al reported no mutational alteration in the Axin1 gene in OSCC (15), while Iwai et al found that 
Table I. Correlation of Axin1 staining with clinicopathological parameters in OSCC.

\begin{tabular}{lcccc}
\hline & \multicolumn{4}{c}{ Axin1 staining } \\
\cline { 2 - 5 } Variables & No. & $+(\%)$ & $-(\%)$ & p-value \\
\hline Total no. & 44 & 11 & 33 & \\
Gender & & & & \\
Male & 28 & 4 & 24 & 0.070 \\
Female & 16 & 7 & 9 & \\
Histological grading & & & & \\
I-II & 27 & 10 & 17 & \\
III & 17 & 1 & 16 & 0.049 \\
Tumor stage & & & & \\
T1+T2 & 26 & 7 & 19 & \\
T3+T4 & 18 & 4 & 14 & 1.000 \\
Nodal stage & & & & \\
N0 & 24 & 9 & 15 & 0.036 \\
N1-3 & 20 & 2 & 18 & \\
\hline
\end{tabular}

the Axin1 gene may be one of the mutational targets in OSCC (16). In this study, we performed mutation analysis in the Axin1 gene by DHPLC and DNA sequencing in primary OSCC from Chinese patients. Furthermore, Axin1 protein expression was also investigated by immunohistochemistry in the specimens of those patients with primary OSCC, including well to poorly differentiated carcinomas with or without metastasis, in order to explore the roles of the Axin1 gene in OSCC carcinogenesis and metastasis.

\section{Materials and methods}

Patients and samples. Surgical specimens were obtained from 44 patients (28 males and 16 females) with primary OSCC, who underwent potentially curative surgery at the Department of Surgery, Peking University School of Stomatology during 2002-2005. None of these patients had received irradiation or chemotherapy before surgery. The clinical and pathological characteristics of these patients are summarized in Table I. The age range of the patients was 34-76 years, and the mean age was 57.3 years. Tumor stage and nodal metastasis stage were classified according to the fifth edition of the TNM Classification of the International Union Against Cancer (UICC). Histopathological diagnosis was made routinely at the Department of Oral Pathology, Peking University School of Stomatology. This study was conducted with informed consent of the patients.

DNA preparation and PCR. Small pieces of tumor tissue and nearby non-cancerous squamous mucosa tissue were frozen in liquid nitrogen and stored at $-80^{\circ} \mathrm{C}$ until DNA extraction. Genomic DNA from the frozen samples $(25 \mathrm{mg})$ was extracted using the DNeasy tissue kit (Qiagen, Hilden, Germany), according to the manufacturer's recommendations. For
Table II. Sequences of primers for the amplification of the Axin1 gene.

\begin{tabular}{|c|c|c|}
\hline Primer & Sequence $\left(5^{\prime}-3^{\prime}\right)$ & $\begin{array}{c}\text { Size of } \\
\text { product (bp) }\end{array}$ \\
\hline \multirow[t]{2}{*}{ Exon 1.1} & Forward CGACTTGCTGGACTTCTGGT & 547 \\
\hline & Reverse TCACCTGAACTCTCTGCCTT & \\
\hline \multirow[t]{2}{*}{ Exon 1.2} & Forward TCATTGTTCCTTGACGCAGA & 469 \\
\hline & Reverse CTTTCGGTAGATGGCTCTCG & \\
\hline \multirow[t]{2}{*}{ Exon 2} & Forward TCACTAACATGCCCTGCTTG & 227 \\
\hline & Reverse ACCGGACTTACACACTGCTG & \\
\hline \multirow[t]{2}{*}{ Exon 3} & Forward CTGAGTTAACGGCTGCCTCT & 252 \\
\hline & Reverse TTACGGGAATGTGAGGTAGG & \\
\hline \multirow[t]{2}{*}{ Exon 4} & Forward TAGCCTGTGACCTTTCAACC & 266 \\
\hline & Reverse GAAGAACATCAGGACATCCC & \\
\hline \multirow[t]{2}{*}{ Exon 5.1} & Forward ACGGGAAGCACGTACCCAAGTCA & 322 \\
\hline & Reverse ATGAGGAGGTTCTGGCCTTCTGC & \\
\hline \multirow[t]{2}{*}{ Exon 5.2} & Forward ACGGGAAGCACGTACCCAAGTCA & 516 \\
\hline & Reverse ATGAGGAGGTTCTGGCCTTCTGC & \\
\hline \multirow[t]{2}{*}{ Exon 6} & Forward AGCCTTACAGATGCCAGGAG & 356 \\
\hline & Reverse ACACACTGAAGCTGCACACA & \\
\hline \multirow[t]{2}{*}{ Exon 7} & Forward GATGAGTGTAGCCCCACCAG & 308 \\
\hline & Reverse TACCTCTGCTTGGAGGGTGC & \\
\hline \multirow[t]{2}{*}{ Exon 8} & Forward GGCACAGCCACCTTTGAC & 161 \\
\hline & Reverse ACCCTCAGGACGCACGTA & \\
\hline \multirow[t]{2}{*}{ Exon 9} & Forward GTACCACCGCTGCATCTCTT & 212 \\
\hline & Reverse CCAGCCCTCACACTCACC & \\
\hline \multirow[t]{2}{*}{ Exon 10} & Forward CTCACTGCCCTCCTCACCT & 172 \\
\hline & Reverse CCAGCCCACCAGCCTATC & \\
\hline
\end{tabular}

detection of the mutation alterations in the Axin 1 gene, we sequenced the whole coding areas and exon-intron junction regions. The sequences of the primers are shown in Table II. All amplifications were performed in $50 \mu 1 \mathrm{PCR}$ volume containing $100 \mathrm{ng}$ of genomic DNA, $10 \mathrm{mM}$ dNTPs $(2.5 \mathrm{mM}$ each), $1.5 \mathrm{mM} \mathrm{MgCl}_{2}, 0.2 \mu \mathrm{M}$ each primer and $0.25 \mathrm{U}$ Ex-Taq polymerase (Takara, Japan). To the PCRs with the primer sets 2, 5, 7, 9 and 10, DMSO (5\%) was added to increase the amplification efficiency. Every sample was amplified with a hot start of $94^{\circ} \mathrm{C}$ for 5 min followed by 35 cycles of denaturation at $94^{\circ} \mathrm{C}$ for $30 \mathrm{sec}$, annealing at $60^{\circ} \mathrm{C}$ (primer sets 5,6 and 7 at $64^{\circ} \mathrm{C}, 65^{\circ} \mathrm{C}$ and $62^{\circ} \mathrm{C}$, respectively) for $45 \mathrm{sec}$, extension at $72^{\circ} \mathrm{C}$ for $30 \mathrm{sec}$ and a final extension step of $72^{\circ} \mathrm{C}$ for $7 \mathrm{~min}$. The synthesized PCR products were analyzed by $1 \%$ agarose gel electrophoresis.

DHPLC analysis. DHPLC analysis was performed using the WAVE system (TransGenomic, Inc, USA). The PCR products were run both unmixed and mixed 1:1 with a reference (wide 
type) DNA, which was obtained from a conformed sample without Axin1 gene mutation. Samples were subjected to heteroduplex induction as follows: preheating at $95^{\circ} \mathrm{C}$; denaturing for $10 \mathrm{~min}$ at $95^{\circ} \mathrm{C}$; gradually reannealing from $95^{\circ} \mathrm{C}$ to $25^{\circ} \mathrm{C}$ with $1^{\circ} \mathrm{C} / \mathrm{min}$; and storage at $4^{\circ} \mathrm{C}$ before analysis. Aliquots of $5 \mu \mathrm{l}$ of reannealed PCR products were injected for $0.1 \mathrm{~min}$ on a semi-automated 3500 High Throughput Wave system (Transgenomic) using an elution gradient and an oven temperature as predicted by WAVEMAKER Software version 4.1 (Transgenomic). Gradient parameters were optimized according to the length of the product and the melting behavior of a theoretically rearranged product. The mobile phase used $0.1 \mathrm{M}$ triethylammonium acetate (TEAA) solution in water, pH 7.0 (WAVE Optimized buffer A, Transgenomic), and PCR products were eluted for $2 \mathrm{~min}$ at a flow rate of $1.5 \mathrm{ml} / \mathrm{min}$ with an acetonitrile gradient. The gradient was created by mixing buffer $\mathrm{A}$ and $0.1 \mathrm{M}$ TEAA solution in water, $25 \%$ acetonitrile, $\mathrm{pH} 7.0$ (WAVE Optimized buffer B, Transgenomic). Between runs, the column was flushed for $0.1 \mathrm{~min}$ with $75 \%$ acetonitrile in water using the WAVE accelerator and reequilibrated for $0.1 \mathrm{~min}$ at the starting conditions of the gradient. Chromatograms were examined and scored by two operators. Positive controls were tested and correctly identified for each amplicon.

DNA sequencing. All of the PCR fragments showing altered variants in DHPLC screening were gel-purified with a Gel Extraction kit (Omega Bio-Tek, Doraville, USA) according to the manufacturer's protocol and directly sequenced using the same primers as those used for the original PCR amplification. Further mutation detection was pursued in a subset of samples by cloning purified PCR product into plasmid vector pGEM-T (Promega, Madison, USA). After transformation into competent E. coli strain TOP10, colonies carrying recombinant plasmid were picked, and the plasmid DNA was isolated using a Plasmid Miniprep kit (Sigma). Plasmid DNA was sequenced using M13 universal forward and reverse primers. Sequencing analysis was performed on an ABI PRISM 3100 Genetic Analyzer (Applied Biosystems). Any mutation detected was confirmed by reverse sequencing and by analysis in samples from at least two independent PCRs.

Immunohistochemistry. Formalin-fixed and paraffin-embedded OSCC specimens were cut into 5- $\mu \mathrm{m}$ thick sections, mounted on poly-L-Lysine coated slides, deparaffinised in xylene and rehydrated through a graded ethanol series. To quench endogenous peroxidase, sections were incubated with fresh $3 \% \mathrm{H}_{2} \mathrm{O}_{2}$ in methanol for $30 \mathrm{~min}$ at room temperature, and then antigen retrieval was performed by microwave treatment for $20 \mathrm{~min}$ in $0.01 \mathrm{M}$ citrate buffer ( $\mathrm{pH} \mathrm{6.0)}$ ). After washing thrice in PBS, sections were pre-incubated with goat serum for $30 \mathrm{~min}$ at room temperature to prevent non-specific protein binding. Sections were incubated overnight at $4^{\circ} \mathrm{C}$ in a moist chamber with a rabbit polyclonal anti-human Axin1 antibody (Zymed Laboratories, San Francisco, CA, USA; $1: 100,2 \mathrm{~h}$, room temperature), and then incubated with goat anti-rabbit immunoglobin for $30 \mathrm{~min}$ at room temperature following washing thrice in PBS again. Staining was performed with a strepavidin-biotin peroxidase kit (Histotain-Bulk-SP
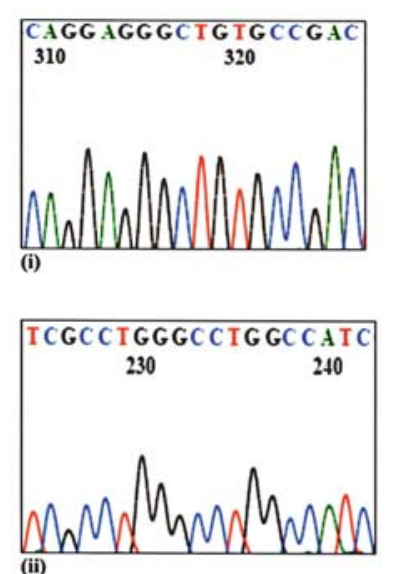

(ii)
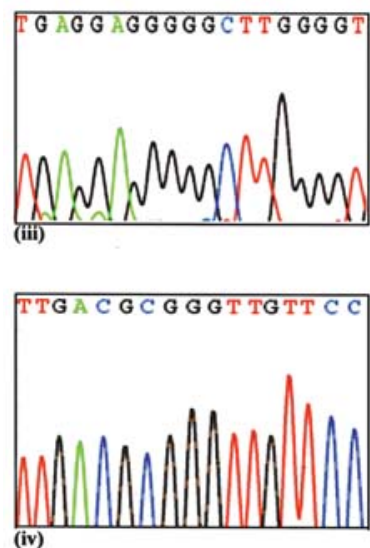
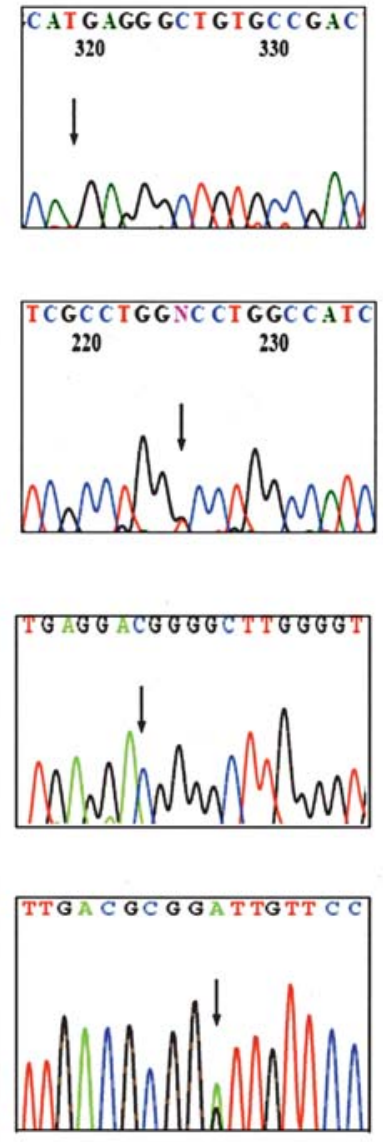

Figure 1. Four mutations identified in the Axin1 gene. (i) The wild-type (left) and the $\mathrm{T}>\mathrm{G}$ substitution at codon 108 in exon 1 (right). (ii) The wildtype (left) and the G>T heterozygous mutation at codon 488 in exon 5 (right). (iii) The wild-type (left) and the $\mathrm{C}>\mathrm{G}$ substitution at intron 5+26 position (right). (iv) The wild-type (left) and the $\mathrm{A}>\mathrm{G}$ heterozygous mutation in intron 7 (right).

kit, Zymed, South San Francisco, CA, USA), and sites of bound antibody were visualized using liquid DAB + substrate + chromogen system. The sections were lightly counterstained with Mayer's haematoxylin. Control slides included in each experiment consisted of tissue previously shown to express the protein of interest as positive controls; negative controls were prepared by substituting PBS for each primary antibody, and no detectable staining was evident.

Evaluation of Axin1 expression. The immunoreactivity of Axin1 protein staining was scored according to the percentage of positively stained tumor cells. According to previous studies, the score was ranked as follows: when $\geq 50 \%$ of the tumor cells in a given specimen were positively stained to the same degree as normal epithelium, the sample was graded as Axin1 preserved and scored as positive; when $<50 \%$ of the tumor cells were stained to the same degree as normal epithelium, the sample was graded as having reduced expression and scored as negative.

Statistical analyses. Clinicopathological data were statistically analyzed using the $\chi^{2}$ test. A p-value of $\leq 0.05$ was accepted as significant. 

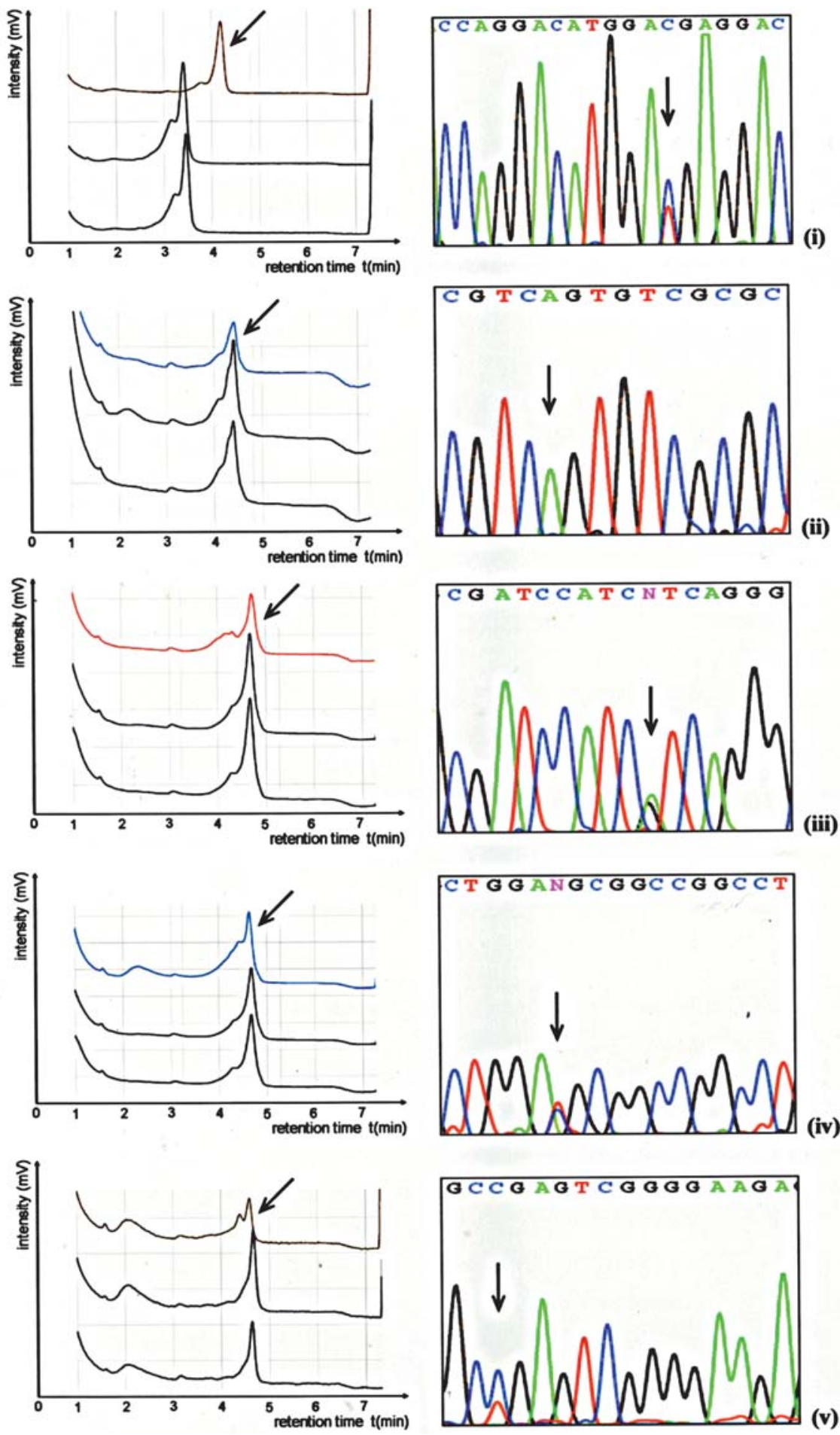

Figure 2. Five polymorphisms identified in the Axin1 gene. Arrows show the genetic alterations found by DHPLC screening (left) and DNA sequencing (right). (i) Codon 254 (GAT $\rightarrow$ GAC), (ii) intron 4+17 (G>A), (iii) condon 429 (GTC $\rightarrow$ ATC), (iv) condon 525 (GAC $\rightarrow$ GAT), (v) codon 609 (GCT $\rightarrow$ GCC).

\section{Results}

Mutation analysis of the Axinl gene. The cancerous and noncancerous samples were analyzed for mutations in all exons and exon-intron junctions in the Axin1 gene by DHPLC and direct sequencing. DHPLC screening identified heterozygous elution profiles showing multiple peaks, and aberrant profiles were shown in 26 different OSCC cases. After sequencing analysis of the PCR products, four mutations and five polymorphisms were identified. DNA samples of case 3 , one case of poor-differentiated OSCC with metastasis, contained two mutations: one revealed a $\mathrm{T}>\mathrm{G}$ substitution at nucleotide 324 in exon 1 resulting in a glycine to stop codon substitution at amino acid residue 108; the other revealed a $A>G$ heterozygous mutation in intron 7 , located very near to exon 8 . In another two patients with moderate-differentiated OSCC and metastasis (cases 42 and 26), a $\mathrm{G}>\mathrm{T}$ heterozygous mutation at codon 488 in exon 5 and a $\mathrm{C}>\mathrm{G}$ substitution at intron $5+26$ position was identified, respectively (Fig. 1). In addition, five polymorphisms were also detected and they are all very frequent, 
Table III. Clinicopathological profile of the cases with mutation alterations in the Axin 1 gene.

\begin{tabular}{|c|c|c|c|c|c|c|c|}
\hline Case & Codon & Mutation & Age & Gender & Histological grading & Tumor stage & Nodal stage \\
\hline 3 & 108 & $\mathrm{~T}>\mathrm{G}$ & 41 & Male & III & $\mathrm{T} 2$ & $\mathrm{~N} 2$ \\
\hline 3 & Intron 7 & $A>G$ & 41 & Male & III & $\mathrm{T} 2$ & $\mathrm{~N} 2$ \\
\hline 26 & Intron 5 & $\mathrm{C}>\mathrm{G}$ & 74 & Male & II & $\mathrm{T} 2$ & $\mathrm{~N} 2$ \\
\hline 42 & 488 & $\mathrm{G}>\mathrm{T}$ & 76 & Male & II & $\mathrm{T} 2$ & $\mathrm{~N} 2$ \\
\hline
\end{tabular}

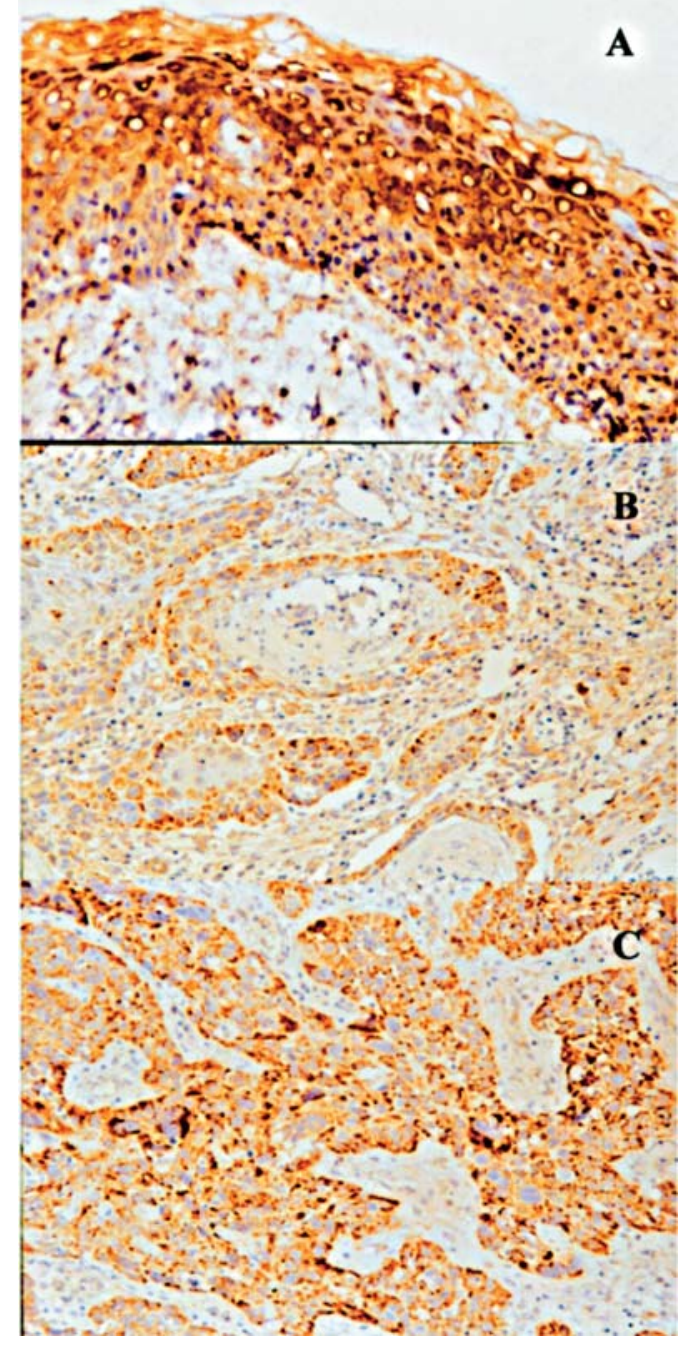

Figure 3. Immunohistochemical staining of Axin1. (A) Immunoreactivity for Axin1 was strongly positive in normal stratified squamous epithelium and localized in the cytoplasm. (B) Immunohistochemical staining showed positive staining of Axin1 in well-differentiated OSCC with brown granules in the cytoplasm of the positive tumor cells. (C) Immunohistochemical staining showed preserved expression of Axin 1 in moderate OSCC with positive staining to the same degree as normal epithelium and localized in the cytoplasm.

localizing at positions of codon $254(\mathrm{GAT} \rightarrow \mathrm{GAC})$, codon $429(\mathrm{GTC} \rightarrow \mathrm{ATC})$, codon $525(\mathrm{GAC} \rightarrow \mathrm{GAT})$, codon 609 $(\mathrm{GCT} \rightarrow \mathrm{GCC})$, and intron $4+17(\mathrm{G}>\mathrm{A})$, with a frequency of $39 \%, 8 \%, 6 \%, 13 \%$ and $9 \%$, respectively (Fig. 2). All the mutations were confirmed in their respective tumor tissues by another round of PCR and sequencing analysis. The results are shown in Tables III and IV.
Table IV. Sequence alterations and frequency in Axin1 gene polymorphisms.

\begin{tabular}{lcccc}
\hline Exon & Codon & Polymorphism & $\begin{array}{c}\text { Amino acid } \\
\text { change }\end{array}$ & $\begin{array}{c}\text { Frequency } \\
\text { (chromosomes) }\end{array}$ \\
\hline 1 & 254 & GAT $\rightarrow$ GAC & Asp & $34 / 88(39 \%)$ \\
Intron 4 & & G $>$ A & & $8 / 88(9 \%)$ \\
5 & 429 & GTC $\rightarrow$ ATC & Val $\rightarrow$ Ile & $7 / 88(8 \%)$ \\
5 & 525 & GAC $\rightarrow$ GAT & Asp & $5 / 88(6 \%)$ \\
6 & 609 & GCT $\rightarrow$ GCC & Ala & $11 / 88(13 \%)$ \\
\hline
\end{tabular}

Immunohistochemistry of Axin1. Immunoreactivity for Axin1 was strongly positive in normal stratified squamous epithelium and localized in the cytoplasm (Fig. 3A). Significantly reduced expression of Axin 1 was shown in most of the 44 primary tumors (33/44). Some samples of well to moderately differentiated oral squamous cell carcinoma had an Axin1 preserved expression with positive staining to the same degree as normal epithelium and localized in the cytoplasm of the tumor cells, while only one case of poorly differentiated oral squamous cell carcinoma showed Axin1-positive staining (Fig. 3B and C). The other cases with poorly differentiated oral squamous cell carcinoma showed a diffused decrease in Axin1 expression.

Relation between Axin1 expression and clinicopathological features. The correlation between the clinicopathological characteristics of patients with oral squamous cell carcinoma and the expression of Axin 1 in their tumor tissues is also summarized in Table I. Although there was no significant association between Axin1 expression and patient age, gender or tumor stage, there were significant inverse correlations between Axin1 expression and lymph node metastasis $(\mathrm{p}=0.036)$, and histological grading $(\mathrm{p}=0.049)$.

\section{Discussion}

Axin is a multidomain scaffold protein that has many functions in biological signaling pathways. Overexpression of Axin1 results in axis duplication in mouse embryos. Wnt signaling activity determines dorsal-ventral axis formation in vertebrates, implicating Axin as a negative regulator for this signaling pathway, which promotes phosphorylation and ubiquitination of $\beta$-catenin, thus inhibiting $\beta$-catenin shuttling from cytoplasm to nucleus and controlling cell proliferation $(17,18)$. 
Axin1 (also simply called Axin), which encodes isoforms $\mathrm{a}$ and $\mathrm{b}$, and Axin2 (also called Axil or Conductin) have 45\% identity at the nucleotide level, and the proteins they encode appear to be functionally similar (19). However, Axin1 is the constitutively expressed component of the B-catenin degradation complex and is essential for the maintenance of low Wnt signaling activity in the basal state. Axin 1 is composed of 10 exons, containing several domains that mediate direct binding to low density lipoprotein related protein receptor, the Frizzled co-receptor $(20,21)$, APC (which appears to assist Axin in recruiting $\beta$-catenin to the Axin complex) (22), GSK3ß/ $\alpha$ (23), ß-catenin, DVL (24), MEKK1 (25), CKI (26), protein phosphatase $2 \mathrm{~A}$ (PP2A) (27), frequently rearranged in advanced $\mathrm{T}$ cell lymphomas (Frat1) (28), and a homodimerisation domain (29). Although previous reports have shown the Axin gene to be mutated in several primary human cancers, few studies reported the mutation and expression of Axin in oral squamous cell carcinoma. Therefore, we investigated the association between Axin gene mutation and expression in oral squamous cell carcinoma.

In the present study, we examined mutations in all the 10 exons and exon-intron junctions of the Axin1 gene in 44 primary OSCC samples with four mutations and five polymorphisms identified. One of the poor-differentiated OSCC cases with metastasis contained two mutations: one revealed a $\mathrm{T}>\mathrm{G}$ substitution at nucleotide 324 in exon 1 resulting in a glycine to stop codon substitution at amino acid residue 108, and the other revealed an $A>G$ heterozygous mutation in intron 7 , locating very near to exon 8 . In addition, one of the five polymorphisms identified was also located in exon 1 , at the position of codon 254 (GAT $\rightarrow$ GAC) with a frequency of $39 \%$. According to the previous study, the region of Axin1 involved in APC binding is in exon 1, which shows significant homology to members of the regulators of $G$ protein signaling (RGS) family and is named RGS domain subsequently (30). The mutation and polymorphism of the Axin1 gene that we found in its RGS domain may influence the binding of APC to Axin1 that is required for the efficient downregulation of B-catenin by APC. As a result, the accumulated B-catenin may interact with $\mathrm{T}$ cell factor/lymphoid enhancer factor (TCF/ LEF), activating their transcriptional activity and controlling cell proliferation in tumor progression.

Furthermore, we identified 4 genetic alterations in the B-catenin binding domain of the Axin1 gene: two mutations localizing at codon 488 and intron 5, respectively; two polymorphisms at codon 429 and codon 525, with a frequency of $8 \%$ and $6 \%$, respectively. Wnt signaling has been shown to be activated in several carcinomas including oral squamous cell carcinoma, with its central factor B-catenin increasing in cytoplasm and/or translocating into cell nucleus. Uraguchi et al reported no $\beta$-catenin mutation in the cases of oral squamous cell carcinoma that had $\beta$-catenin nuclear/cytoplasmic expression patterns (31). It is known that the phosphorylation of $B$-catenin is required for its ubiquitination and degradation by 26 s proteasome. Axin 1 makes a complex with GSK-3ß, B-catenin, APC and other binding partners, acting as a scaffold protein for the assembly of the multi-protein complex, and promotes GSK-3ß-dependent phosphorylation of B-catenin. Axin1 can also interact directly with B-catenin and promote its phosphorylation by CKI $\alpha$ (32). Considering that Uraguchi et al found no B-catenin mutation in the cases of oral squamous cell carcinoma that had $\beta$-catenin nuclear/cytoplasmic expression patterns, Axin 1 genetic alterations in the $\beta$-cateninbinding domain found in our OSCC cases might interpret the aberrant cytoplasmic expression of $\beta$-catenin in OSCC. In addition, we also found two previously published singlenucleotide polymorphisms, localizing at codon 609 and intron $4+17$.

We also performed immunohistochemical analysis for the expression of Axin 1 in these 44 cases of OSCC. Our results showed reduced expression of Axin 1 in most of the 44 primary tumors and there were significant inverse correlations between Axin1 expression and lymph node metastasis, and histological grading in OSCC. As a negative regulator for Wnt signaling and a positive regulator for SAPK/JNK and TGF- $\beta$ signaling, the Axin1 gene might be able to reduce cell proliferation and induce cell differentiation and apoptosis, and subsequently play a pivotal role in carcinogenesis. In the case of HCC cell lines, the introduction of the Axin1 normal gene appeared to induce programmed cell death (33). To ascertain whether the Axin1 mutations found in OSCC are biologically important, biochemical and functional studies are required to elucidate their effects on the growth and differentiation of the cancer cells.

In conclusion, a high frequency of genetic alterations in the Axin1 gene was shown in oral squamous cell carcinoma, together with reduced expression of Axin 1 in tumor progression, suggesting that Axin1 may play a pivotal role in carcinogenesis. Biochemical and functional studies are required to elucidate its mechanism.

\section{Acknowledgments}

This study was supported by a research grant from National Nature Science Foundation of China (30471894).

\section{References}

1. Zeng L, Fagotto F, Zhang T, et al: The mouse Fused locus encodes axin, an inhibitor of the Wnt signaling pathway that regulates embryonic axis formation. Cell 90: 181-192, 1997.

2. Wodarz A and Nusse R: Mechanisms of Wnt signaling in development. Annu Rev Cell Dev Biol 14: 59-88, 1998.

3. Bienz $M$ and Clever H: Linking colorectal cancer to Wnt signaling. Cell 103: 311-320, 2000.

4. Ikeda S, Kishida S, Yamamoto H, et al: Axin, a negative regulator of the Wnt signaling pathway, forms a complex with GSK-3beta and beta-catenin and promotes GSK-3beta-dependent phosphorylation of beta-catenin. EMBO J 17: 1371-1384, 1998 .

5. Kishida S, Yamamoto $\mathrm{H}$, Ikeda $\mathrm{S}$, et al: Axin, a negative regulator of the Wnt signaling pathway, directly interacts with adenomatous polyposis coli and regulates the stabilization of beta-catenin. J Biol Chem 273: 10823-10826, 1998.

6. Heldin $\mathrm{CH}$, Miyazono $\mathrm{K}$ and ten Dijke P: TGF-beta signaling from cell membrane to nucleus through SMAD proteins. Nature 390: 465-471, 1997.

7. Furuhashi M, Yagi K, Yamamoto $\mathrm{H}$, et al: Axin facilitates Smad3 activation in the transforming growth factor beta signaling pathway. Mol Cell Biol 21: 5132-5141, 2001.

8. Nishita M, Hashimoto MK, Ogata $\mathrm{S}$, et al: Interaction between Wnt and TGF-beta signaling pathways during formation of Spemann's organizer. Nature 403: 781-785, 2000.

9. Zhang Y, Neo SY, Han J, et al: Dimerization choices control the ability of axin and disheveled to activate c-Jun N-terminal kinase/ stress-activated protein kinase. J Biol Chem 275: 25008-25014, 2000 . 
10. Raybaud-Diogene H, Tetu B, Morency R, Fortin A and Monteil RA: P53 overexpression in head and neck squamous cell carcinoma: review of the literature. Eur J Cancer B Oral Oncol 32: 143-149, 1996.

11. Taniguchi K, Roberts LR, Aderca IN, et al: Mutational spectrum of beta-catenin, AXIN1, and AXIN2 in hepatocellular carcinomas and hepatoblastoma. Oncogene 21: 4863-4871, 2002.

12. Wu R, Zhai Y, Fearon ER, et al: Diverse mechanisms of betacatenin deregulation in ovarian endometrioid adenocarcinomas. Cancer Res 61: 8247-8255, 2001.

13. Shimizu Y, Ikeda S, Fujimori M, et al: Frequent alterations in the Wnt signaling pathway in colorectal cancer with microsatellite instability. Genes Chromosomes Cancer 33: 73-81, 2002.

14. Jin LH, Shao QJ, Luo W, et al: Detection of point mutations of the Axin1 gene in colorectal cancers. Int J Cancer 107: 696-699, 2003.

15. Yeh KT, Chang JG, Lin TH, Wang YF, Chang JY, Shih MC and Lin CC: Correlation between protein expression and epigenetic and mutation changes of Wnt pathway genes in oral cancer. Int J Oncol 23: 1001-1007, 2003.

16. Iwai S, Katagiri W, Kong C, Amekawa S, Nakazawa M and Yura Y: Mutations of the APC, beta-catenin, and axin1 genes and cytoplasmic accumulation of beta-catenin in oral squamous cell carcinoma. J Cancer Res Clin Oncol 131: 773-782, 2005.

17. Yamamoto H, Kishida S, Uochi T, et al: Axil, a member of the Axin family, interacts with both glycogen synthase kinase 3 beta and beta-catenin and inhibits axis formation of Xenopus embryos. Mol Cell Biol 18: 2867-2875, 1998.

18. Cong F and Varmus H: Nuclear-cytoplasmic shuttling of Axin regulates subcellular localization of beta-catenin. Proc Natl Acad Sci USA 101: 2882-2887, 2004.

19. Mai M, Qian C, Yokomizo A, et al: Cloning of the human homolog of conductin (AXIN2), a gene mapping to chromosome 17q23-q24. Genomics 55: 341-344, 1999.

20. Mao J, Wang J, Liu B, et al: Low-density lipoprotein receptorrelated protein- 5 binds to Axin and regulates the canonical Wnt signaling pathway. Mol Cell 7: 801-809, 2001.

21. Tolwinski NS, Wehrli M, Rives A, et al: Wg/Wnt signal can be transmitted through arrow/LRP5,6 and Axin independently of Zw3/Gsk3beta activity. Dev Cell 4: 407-418, 2003.
22. Behrens J, Jerchow BA, Wurtele M, et al: Functional interaction of an axin homolog, conductin, with beta-catenin, APC, and GSK3beta. Science 280: 596-599, 1998.

23. Li L, Yuan H, Weaver CD, et al: Axin and Frat1 interact with dvl and GSK, bridgingDvl to GSK in Wnt-mediated regulation of LEF-1. EMBO J 18: 4233-4240, 1999.

24. Kishida S, Yamamoto H, Hino S, et al: DIX domains of Dvl and axin are necessary for protein interactions and their ability to regulate beta-catenin stability. Mol Cell Biol 19: 4414-4422, 1999.

25. Zhang Y, Neo SY, Wang X, et al: Axin forms a complex with MEKK1 and activates c-Jun NH(2)-terminal kinase/stressactivated protein kinase through domains distinct from Wnt signaling. J Biol Chem 274: 35247-35254, 1999.

26. Zhang Y, Qiu WJ, Chan SC, et al: Casein kinase I and casein kinase II differentially regulate axin function in Wnt and JNK pathways. J Biol Chem 277: 17706-17712, 2002.

27. Hsu W, Zeng L and Costantini F: Identification of a domain of axin that binds to the serine/threonine protein phosphatase $2 \mathrm{~A}$ and a self-binding domain. J Biol Chem 274: 3439-3445, 1999.

28. Farr GH III, Ferkey DM, Yost C, et al: Interaction among GSK-3, GBP, axin, and APC in Xenopus axis specification. J Cell Biol 148: 691-702, 2000.

29. Sakanaka $C$ and Williams LT: Functional domains of axin. Importance of the $\mathrm{C}$-terminus as an oligomerization domain. $\mathrm{J}$ Biol Chem 274: 14090-14093, 1999.

30. Rubinfeld B, Robbins P, El-Gamil M, et al: Stabilization of beta-catenin by genetic defects in melanoma cell lines. Science 275: 1790-1792, 1997.

31. Uraguchi M, Moorikawa M, Shirakawa M, Sanada K and lmai K: Activation of Wnt family expression and signaling in squamous cell carcinomas of the oral cavity. J Dent Res 84: 327-332, 2004.

32. Amit S, Hatzubai A, Birman Y, et al: Axin-mediated CKI phosphorylation of beta-catenin at Ser 45: a molecular switch for the Wnt pathway. Genes Dev 16: 1066-1076, 2002.

33. Satoh S, Daigo Y, Furukawa Y, et al: AXIN1 mutations in hepatocellular carcinomas, and growth suppression in cancer cells by virus-mediated transfer of AXIN1. Nature Genetics 24: 245-250, 2000. 